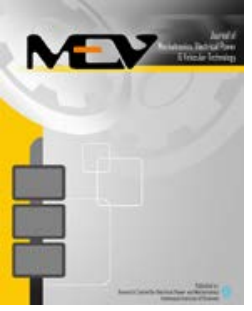

Journal of Mechatronics, Electrical Power, and Vehicular Technology

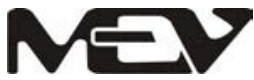

\title{
DERIVATIVE LOAD VOLTAGE AND PARTICle SWARM OPTIMIZATION TO DETERMine OPTIMUM SizING AND Placement OF SHUNT CAPACITOR IN IMPROVING LINE LOSSES
}

\author{
Mohamed Milad Baiek a , Ahmad E. Esmaio a , Muhammad Nizam ${ }^{\text {a,* }}$, \\ Miftahul Anwar ${ }^{a}$, Hasan M. S. Atia ${ }^{b}$ \\ ${ }^{\mathrm{a}}$ Postgraduate program, Mechanical Engineering Department, Sebelas Maret University \\ Jl. Ir. Sutami No. 36-A Surakarta, Indonesia \\ ${ }^{\mathrm{b}}$ General Electricity Company of Libya (GECOL), \\ GECOL Building, Jamahiriya Area 668 Tarabulus, Tripoli, Libya
}

Received 01 April 2016; received in revised form 25 April 2016; accepted 03 May 2016 Published online 23 December 2016

\begin{abstract}
The purpose of this research is to study optimal size and placement of shunt capacitor in order to minimize line loss. Derivative load bus voltage was calculated to determine the sensitive load buses which further being optimum with the placement of shunt capacitor. Particle swarm optimization (PSO) was demonstrated on the IEEE 14 bus power system to find optimum size of shunt capacitor in reducing line loss. The objective function was applied to determine the proper placement of capacitor and get satisfied solutions towards constraints. The simulation was run over Matlab under two scenarios namely base case and increasing $100 \%$ load. Derivative load bus voltage was simulated to determine the most sensitive load bus. PSO was carried out to determine the optimum sizing of shunt capacitor at the most sensitive bus. The results have been determined that the most sensitive bus was bus number 14 for the base case and increasing 100\% load. The optimum sizing was 8.17 Mvar for the base case and 23.98 Mvar for increasing load about $100 \%$. Line losses were able to reduce approximately $0.98 \%$ for the base case and increasing $100 \%$ load reduced about $3.16 \%$. The proposed method was also proven as a better result compared with harmony search algorithm (HSA) method. HSA method recorded loss reduction ratio about $0.44 \%$ for the base case and $2.67 \%$ when the load was increased by $100 \%$ while PSO calculated loss reduction ratio about $1.12 \%$ and $4.02 \%$ for the base case and increasing 100\% load respectively. The result of this study will support the previous study and it is concluded that PSO was successfully able to solve some engineering problems as well as to find a solution in determining shunt capacitor sizing on the power system simply and accurately compared with other evolutionary optimization methods
\end{abstract}

Keywords: particle swarm optimization; shunt capacitor; line losses.

\section{INTRODUCTION}

Distribution system planning is an important issue in power engineering. The term distribution system consists of low voltage (LV) and medium voltage (MV) networks. Planning of MV network is to identify the location and size of distribution substations and MV feeders. The objective of MV network planning is to minimize the investment cost along with the line loss and reliability indices such as system average interruption duration index (SAIDI) and system

* Corresponding Author.Tel: +62 271632163

E-mail: nizam_kh@ieee.org average interruption frequency index (SAIFI). There are several limitations which should be satisfied during the planning procedure.

The bus voltage as a constraint should be maintained within a standard range. The actual feeder current should be less than the rated current of the feeder [1]. The voltage drop along radial distribution systems has been a crucial operating problem. Utilities look for solutions for this problem, from both technical and economical standpoints. Various devices such as capacitors and voltage regulators (VR's) can be installed to reduce the voltage drop. 
Several researchers have used soft computing techniques to find an optimal solution for the DC location. A number of these methods used heuristic search methods while some others formulate the problem as a general optimization problem [2-4]. However, the general formulation of this problem is quite complicated necessitating computational demand solutions. An intelligent method based on a hybrid system of PSO, honey bees mating optimization (HBMO), and Cuckoo search algorithm were proposed to solve the capacitor placement problem [3, 5, 6].

Recently, many evolutionary methods such as GA [3, 4], evolutionary programming [7, 8], stochastic [9], PSO [6, 7, 10] have been applied to solve the power system economic dispatch problem. Generally, evolutionary methods need several trials to achieve optimal or near optimal solution and require special care in the tuning of parameters associated with it.

This research will focus on finding optimum placement at the most sensitive bus and proposing optimum sizing using PSO to improve the line losses in the IEEE 14 bus power system. A mathematical model of derivative function was used to determine the sensitive load buses. Further, the range of PSO is divided to some localities. The individual minimum and global minimum of the cost function is saved in memory, along with the corresponding particle position (in our case, shunt capacitor position). The particle position is updated in which near the position towards the individual minimum and global minimum, according to pre-specified weights assigned. In this way, the optimum sizing can be achieved.

\section{BASIC THEORY}

\section{A. Particle Swarm Optimization}

Particle swarm optimization (PSO) is a population-based stochastic optimization technique developed by Dr. Eberhart and Dr. Kennedy in 1995, inspired by social behavior of bird flocking or fish schooling. The potential solutions, called particles, fly through the problem space by following the current optimum particles. Each particle keeps track of its coordinates in the problem space which is associated with the best solution (fitness) it has achieved so far (the fitness value is also stored). This value is called pbest. Another "best" value that is tracked by the particle swarm optimizer is the best value, obtained so far by any particle in the neighbors of the particle.

This location is called lbest. When a particle takes all the population as its topological neighbors, the best value is a global best, and this is called gbest. The PSO concept consists of, at each time step, changing the velocity (accelerating) of each particle toward its pbest and gbest locations (local version of PSO). Acceleration is weighted by a random term, with separate random numbers being generated for acceleration toward pbest and lbest locations [6, 7]. The flowchart of the PSO algorithm is shown in Figure 1.

Understanding the conceptual basis of the PSO, the steps are explained. First, define the solution space to pick the parameters that need to be optimized and give them a reasonable range to search for the optimal solution. This is referred to $\mathrm{X}_{\min } \mathrm{N}$, and $\mathrm{X}_{\max } \mathrm{N}$ respectively, where the range is from 1 to $\mathrm{N}$. Second, define a fitness function that provides the link between the optimization algorithm and the physical world. It is critical that a good function is chosen that accurately represents, in a single number, the goodness of the solution.

The fitness function and the solution space must be specifically developed for optimization, and implementation is not depending on the physical system being optimized. Third, initialize random swarm location and velocities. To begin searching for the optimal position in the solution space, each particle begins at its own random location. Since its initial position is the only location encountered by each particle at the starting run, this position becomes each particle's respective pbest. The first gbest is then selected from among these initial positions. Fourth, systematically fly the particles through the

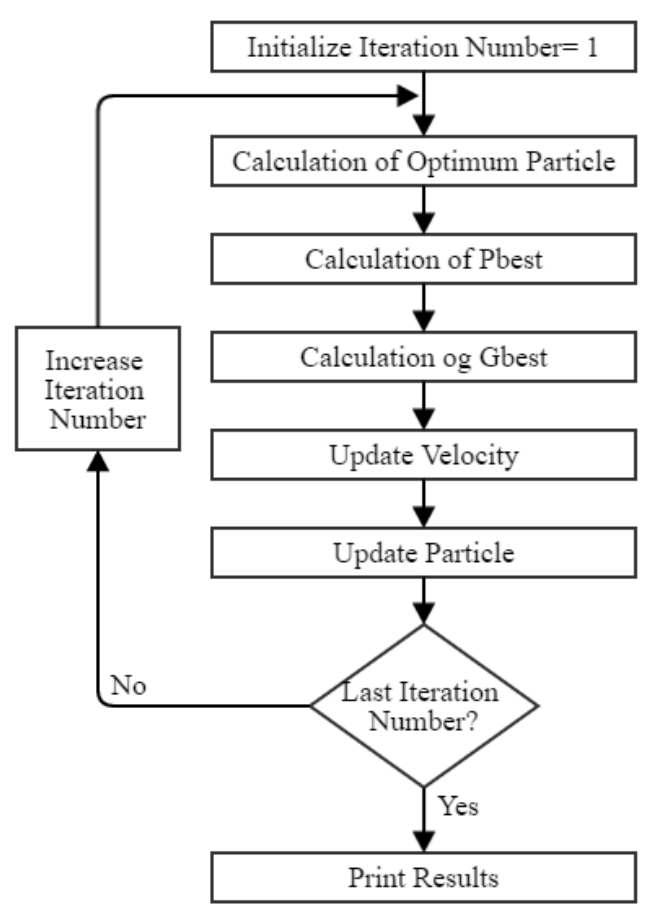

Figure 1. Algorithm of PSO 
solution space. Each particle must then be moved through the solution space as if it was a bee in a swarm. The algorithm acts on each particle one by one, moving it by a small amount and cycling through the entire swarm. The following steps are enacted on each particle individually.

Evaluate the Particle's Fitness: compare to gbest, pbest. The fitness function, using the coordinates of the particle in solution space, returns a fitness value to be assigned to the current location. If the value is greater than the value at the respective pbest for that particle, or the global gbest, then the appropriate locations are replaced with the current location.

Update the Particle's Velocity: the manipulation of a particle's velocity is the core element of the entire optimization. The velocity of the particle is changed according to the relative locations of pbest and gbest. It is accelerated in the directions of these locations of greatest fitness according to Equation (1):

$$
\begin{gathered}
v_{n}=w * v_{n}+c_{1} * \text { rand } *\left(p_{\text {best }, n}-x_{n}\right)+ \\
c_{2} * \text { rand } *\left(g_{\text {best }, n}-x_{n}\right)
\end{gathered}
$$

where $v_{n}$ is the velocity of the particle in the $n^{\text {th }}$ dimension and $x_{n}$ is the particle's coordinate in the $n^{\text {th }}$ dimension, $w$ is inertial weight.

Move the Particle: once the velocity has been determined, it is simple to move the particle to its next location. The velocity is applied for a given time-step, usually chosen to be one and new coordinate is computed for each of the dimensions according to equation (2). The particle is then moved to the location calculated by Equation (2).

$$
x_{n}=x_{n}+\Delta t * v_{n}
$$

The composite nature of this algorithm composed of several independent agents makes it especially conducive to implementation on parallel processors. Next, after this process is carried out for each particle in the swarm, the process is repeated starting from the fourth step. Repetition of this cycle is continued until the termination criteria are met. The criterion most often used in optimizations with the PSO is a maximum iteration number. With this termination condition, the PSO ends when the process starting from the fourth step has been repeated a user-defined number of times.

\section{B. Load Flow Studies}

Load flow studies [11] performed in major areas of power system development and operation because of some reasons. The first reason is load-flow performed to determine the steady state operation of an electric system. It

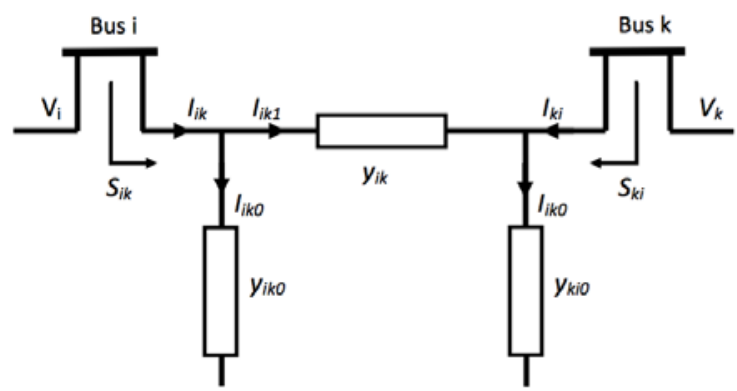

Figure 2. Representations of a line and transformers connected between two buses

calculates voltage drop on each feeder, the voltage at each bus, and the power flow in all branch and feeder circuits. The second reason is to determine the system voltage reminds within specified limits under various contingency conditions, and whether pieces of equipment such as transformers and conductors are overloaded. The third reason is that load flows are often used to identify the need for additional generation, capacitive or inductive AVR support or placement of capacitors and/or reactors to maintain the system voltages within limits. The fourth reason is that losses in each branch and total system power losses are also able to be calculated. It is necessary to plan, economic scheduling and control and existing system as well as planning its future expansion. It allows identification of real and reactive power flows, voltage profiles, power factor and any overloads in the network. This allows engineer to investigate the performance of network under a variety operating condition. Line power flows consider the lines connecting buses $i$ and $k$. The line and the transformers at each end can be represented by a circuit with series admittance $y_{i k}$ and two shunt admittances $y_{i k 0}$ and $y_{k i 0}$ as shown in Figure 2. The current field fed by bus $i$ into the line can be expressed as:

$$
I_{i k}=I_{i k}+I_{i k 0}
$$

where $I_{i k 0}$ is expressed in equation (4)

$$
I_{i k 0}=\left(V_{i}-V_{k}\right) y_{i k}
$$

$V$ is the voltage magnitude at bus, $y$ is admittance in the line,

$$
I_{i k 0}=V_{i} y_{i k 0}
$$

Equation (3) is rewritten as:

$$
I_{i k}=\left(V_{i}-V_{k}\right) y_{k}+V_{i} y_{i k 0}
$$

The power fed into the line from bus $i$ is:

$$
S_{i k}=P_{i k}+Q_{i k}
$$

where $S$ is Power, $P$ is real power and $Q$ is reactive power. 


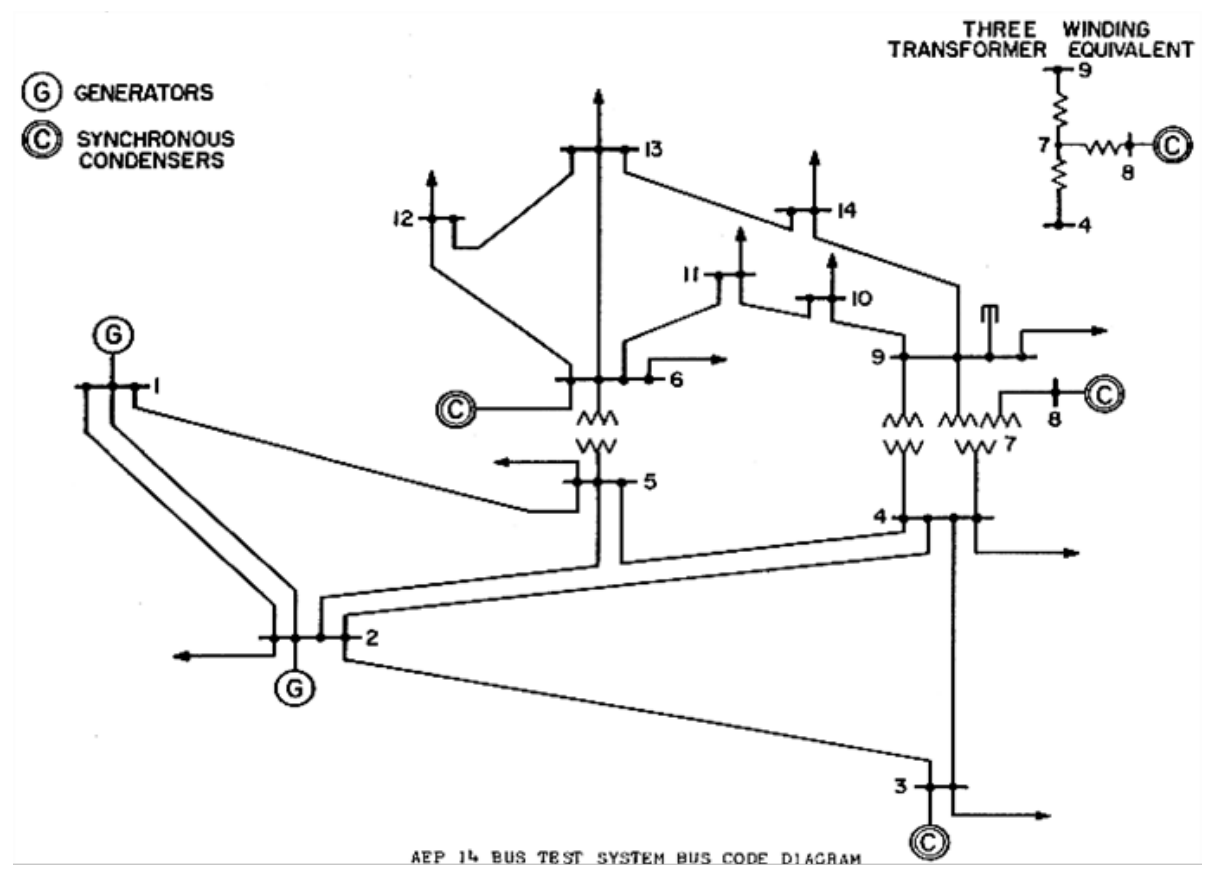

Figure 3. IEEE 14 bus power systems

And,

$$
S_{i k}=V_{i} I_{i k}^{*}
$$

therefore:

$$
S_{i k}=V_{i}\left(V_{i}^{*}-V_{k}^{*}\right) y_{i k}^{*}+V_{i} V_{i}^{*} y_{i k 0}^{*}
$$

power fed into the line from bus $k$ is:

$$
S_{k i}=V_{k}\left(V_{k}^{*}-V_{i}^{*}\right) y_{i k}^{*}+V_{k} V_{k}^{*} y_{k i 0}^{*}
$$

The power loss in the (i-k)th line is the sum of power flows determined from Equation (7) and (8) as follows:

$$
P_{\text {Lik }}=S_{i k}+S_{k i} \text { for all } i, k
$$

The total transmission loss can be computed by summing all the line flows of the power system:

$$
P_{\text {Loss }}=\sum_{l=1}^{n} S_{l}
$$

$P_{\text {Loss }}$ is total power loss, $S_{l}$ is total power fed, where:

$$
S_{l}=S_{i k}+S_{k i}
$$

real (active) and reactive power can be expressed as follows:

$$
\begin{aligned}
& P_{i}=\left|V_{i}\right| \sum_{k=1}^{n}\left|V_{k}\right|\left|Y_{i k}\right| \cos \left(\delta_{i}-\delta_{k}-\theta_{i k 0}\right) \\
& Q_{i}=\left|V_{i}\right| \sum_{k=1}^{n}\left|V_{k}\right|\left|Y_{i k}\right| \sin \left(\delta_{i}-\delta_{k}-\theta_{i k 0}\right)
\end{aligned}
$$

where $\delta$ is phase angle and $\theta$ is load angle.

\section{METHODOLOGY}

This proposed study is to find optimum candidate bus for shunt capacitor placement and determine optimum sizing using PSO. Shunt capacitor functions as compensation device to improve line losses. Total losses of transmission line were calculated using load flow calculation of Newton Raphson method. Shunt capacitor considered to be installed to load buses in order to improve line losses [10].

The IEEE 14 bus power system test of this study, as shown in Figure 3, has been performed over Matlab under two conditions which were the base case and increasing 100\% load. Further, the voltage of each bus can be figured out under both scenarios and calculation of derivative load bus voltage carried out to identify the most sensitive bus where became optimum candidate bus of shunt capacitor placement. Capacitor size was limited beyond the range of 0 to 200 Mvar. Table 1 and Table 2 show the bus position and voltage limit for P-V buses in IEEE 14 bus power system, respectively. Power flows used in this study is to determine line flows and losses. This method determines if the system voltage remains within specified limits under various contingency

Table 1.

Scenario of IEEE 14 bus power system

\begin{tabular}{lll}
\hline $\begin{array}{l}\text { Bus } \\
\text { Code }\end{array}$ & Function & Bus Position \\
\hline 1 & Load buses & $4,5,7,9,10,11,12,13,14$ \\
\hline 2 & Generator bus [3] & $2,3,6,8$ \\
\hline 3 & Slake bus & 1 \\
\hline
\end{tabular}

Table 2.

Voltage limit for P-V buses (p.u.) through controlling AVR

\begin{tabular}{lll}
\hline No Bus & Vmin & Vmax \\
\hline 2 & 0.95 & 1.05 \\
\hline 3 & 0.95 & 1.02 \\
\hline 6 & 0.95 & 1.09 \\
\hline 8 & 0.95 & 1.09 \\
\hline
\end{tabular}


conditions so that the voltages drop on each feeder can be revealed. Load flow calculation was conducted through Equation (13) to (15) to determine the steady state operation of an electric system. It calculates voltage drop on each feeder, voltage at each bus, and the power flow in all branch and feeder circuits.

The second step was to determine the derivative load bus voltage. Derivative load buses voltage calculates the ratio between voltage change at a bus and the change which is caused by increasing load at a bus. The lower value of derivative load bus voltage indicates more sensitive bus. Derivative load bus voltage is calculated using Equation (16).

$$
\frac{d V i}{d l f}=\lim _{l f \rightarrow 0}\left(\frac{\Delta d V i}{\Delta d l f}\right)
$$

where $d V i$ is the small change of voltage magnitude at bus $i$ and $d l f$ is small a change which is caused by load increase.

Next step is to simulate the PSO to determine the shunt capacitor sizing at the most sensitive bus. Besides proposing shunt capacitor at the most sensitive bus, this study also proposes shunt capacitor to install at two buses which were at the most sensitive bus and the second sensitive bus. It carried out to afford more loss reduction on the power system. Parameters of PSO consist of c1 and c2, inertia weight, population size, and iteration. The parameter of c1 and c2 are scaling factors which determine the relative pull of local exploitation (pbest) and global exploration (gbest). Each of this value was 2.0 which has been considered as the best choice and this value become standard in the literature [12] The population is total particles in a swarm. This study has chosen the population of 40 to search the best solution. Inertia weight identifies the extent of particles remind along its own courses without affection of the pull of pbest and gbest. In other words, it purposes to attempt the balance between local exploitation and global exploration.

This study decides inertia weight of 1 with the dumping inertia ratio was 0.99 . Iteration is the repetition of the particles searching solution space until the certain termination criteria of iteration. The iteration of the present study was 400 iterations.

The objective function of the present study was expressed based on the Equation (17).

$$
\begin{aligned}
& P_{\text {Loss }}=\sum_{i=1}^{N} \sum_{\substack{k=1 \\
k \neq i}}^{N} \frac{G i j}{2}\left|V_{i}\right|^{2}+\left|V_{k}\right|^{2}- \\
& 2 V i V k \cos \delta i-\delta k
\end{aligned}
$$

where $P_{\text {Loss }}$ is real power loss, $i$ and $k$ are bus number, $V$ is voltage magnitude, and $\delta$ is phase angle.
Table 3.

Voltage profile at various load

\begin{tabular}{cll}
\hline $\begin{array}{l}\text { Bus } \\
\text { Num. }\end{array}$ & $\begin{array}{l}\text { Voltage Profile } \\
\text { (p.u) of base case }\end{array}$ & $\begin{array}{l}\text { Voltage Profile (p.u) of } \\
\text { Increasing 100\% load }\end{array}$ \\
\hline 1 & 1.06 & 1.06 \\
\hline 2 & 1.045 & 1.045 \\
\hline 3 & 1.01 & 1.01 \\
\hline 4 & 1.018449329 & 0.978022172 \\
\hline 5 & 1.020068977 & 0.981296464 \\
\hline 6 & 1.07 & 1.07 \\
\hline 7 & 1.060890201 & 1.015075462 \\
\hline 8 & 1.09 & 1.09 \\
\hline 9 & 1.054154644 & 0.981174147 \\
\hline 10 & 1.049511205 & 0.980939013 \\
\hline 11 & 1.056152878 & 1.017463192 \\
\hline 12 & 1.055053877 & 1.034729119 \\
\hline 13 & 1.05011979 & 1.020164075 \\
\hline 14 & 1.034393263 & 0.958853595 \\
\hline
\end{tabular}

\section{RESULT AND DISCUSSION}

This simulation study has been conducted to promote voltage profile and line losses in the power system by proposing optimum placement and its optimum size of shunt capacitor on the IEEE 14 bus power system. The optimum placement of capacitor was chosen by determining the sensitive load buses where the voltage drops significantly. Further PSO was applied to determine the sizing of shunt capacitor The shunt capacitor considered to be placed on load buses were bus number $4,5,7,9,10,11,12$, 13 , and 14 . The first scenario was the base case (100\% loads) and the second scenario was done by increasing the load about $100 \%$ (200\% load).

\section{A. IEEE 14 Bus Power System}

Table 3 shows voltage profile before optimization. Voltage profile proposed to be improved by placing shunt capacitor at the most sensitive bus where the high bus voltages drop occurred. PSO was applied to determine the optimum size of shunt capacitor. Voltage profile under normal load and increasing $100 \%$ load has been illustrated clearly in Figure 4. It can be seen

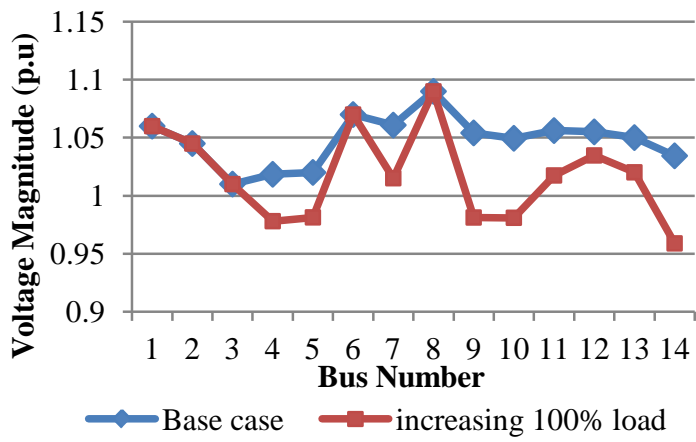

Figure 4. Voltage profile of various load 


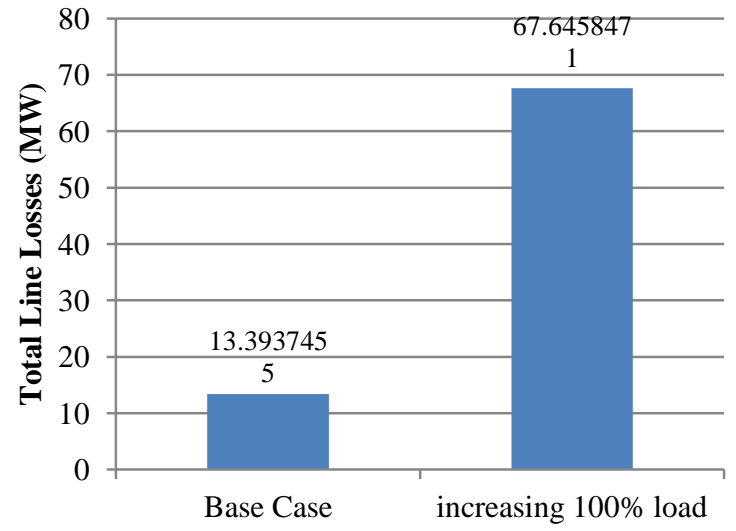

Figure 5. Total line losses of base case and increasing 100\% load

that increasing load will drop voltage profile on the load buses. Figure 5 present line losses of IEEE 14 bus power system testing for the base case and increasing 100\% load. The line losses were taken from transmission line flow distribution. Total line losses of base case attained 13.39375 MW and it was 67.64585 MW for increasing $100 \%$ load. Based on Figure 5, total line loss increase along with the increasing of the load.

\section{B. Optimum Placement of Shunt Capacitor}

Derivative load bus voltage was calculated to determine the optimum candidate bus of shunt capacitor placement. Derivative load bus is the ratio of the change of voltage in respect to load factor. This ratio value indicates the sensitivity of load at buses. The low value of derivative load bus voltage identifies the sensitive bus. Table 4 shows the results of derivative load bus voltage for the base case and increasing 100\% load. The result shows that the lowest value attained at bus no. 14 for both base case and increasing $100 \%$ load. It was -0.05583 for the base case and

Table 4.

Derivative load bus voltage

\begin{tabular}{rlrl}
\hline \multicolumn{2}{c}{ Base Case } & \multicolumn{2}{c}{ Increasing 100\% Load } \\
\hline $\begin{array}{r}\text { Candidate } \\
\text { Bus No. }\end{array}$ & $\begin{array}{l}\text { Derivative } \\
\text { Load Bus } \\
\text { Voltage } \\
\text { (dVi/dLF) }\end{array}$ & $\begin{array}{l}\text { Candidate } \\
\text { Bus No. }\end{array}$ & $\begin{array}{l}\text { Derivative } \\
\text { Load Bus } \\
\text { Voltage } \\
\text { (dVi/dLF) }\end{array}$ \\
\hline 14 & -0.05583 & 14 & -0.07104 \\
\hline 9 & -0.04528 & 9 & -0.06223 \\
\hline 10 & -0.04518 & 10 & -0.06017 \\
\hline 7 & -0.02937 & 5 & -0.04816 \\
\hline 4 & -0.02891 & 4 & -0.04733 \\
\hline 5 & -0.0271 & 7 & -0.04336 \\
\hline 11 & -0.02658 & 11 & -0.03455 \\
\hline 13 & -0.02494 & 13 & -0.02946 \\
\hline 12 & -0.01764 & 12 & -0.02017 \\
\hline & & &
\end{tabular}

Table 5.

Optimum size of shunt capacitor and power losses for base case

\begin{tabular}{lccc}
\hline Optimal Location & $\begin{array}{c}\text { Qc } \\
\text { (Mvar) }\end{array}$ & $\begin{array}{c}\text { PL } \\
\text { (MW) }\end{array}$ & $\begin{array}{l}\text { Loss Reduction } \\
\text { Ratio (\%) }\end{array}$ \\
\hline Bus 14 & 8.1730 & 13.2625 & 0.9801 \\
\hline Buses 14\&9 & 8.3881 & 13.2433 & 1.1234 \\
\hline
\end{tabular}

-0.07104 for increasing $100 \%$ load. Further it followed by bus no. 9, 10, 7, 4, 5, 11, 13, and 12 for the base case. The result of increasing $100 \%$ load was followed by bus no $9,10,5,4,7,11,13$, and 12.

Based on these results, the most sensitive bus has been determined at bus number 14 for either base case or increasing $100 \%$ load. In this study, bus number 14 has been identified as optimum candidate bus for shunt capacitor placement in order to improve line losses on the IEEE 14 bus power system.

\section{Optimum Sizing of Shunt Capacitor}

PSO was proposed to find a solution in finding the optimum size of shunt capacitor to reduce line losses. Simulations have been carried out to get the optimum size for both base case and increasing $100 \%$ load. The simulations carried out beyond two scenarios. First, the optimum location of shunt capacitor allocated on the most sensitive bus which was at bus number 14. Further second scenario simulated with proposing two capacitor placements which were bus number 14 and nine respectively. Placing shunt capacitor at two buses was an aim to get more reduction of losses. Table 5 describes the results of the first scenario which are the optimum capacitor sizing (Qc), power losses, and loss reduction ratio for optimum location at bus number 14. It also can be seen the results of the second scenario for proposing two shunt capacitors at bus number 14 and 9. The first scenario determined the optimum size of shunt capacitor is 8.1730 Mvar and the second scenario is determined about 8.3881 Mvar. The loss reduction ratio was $0.9801 \%$ and $1.1234 \%$ for the first and second scenario respectively.

Figure 6 is the comparison of total line losses before and after shunt capacitor placements. A total line loss without optimization was 13.393 MW, and it decreased up to 13.262 MW by allocating shunt capacitor at the most sensitive bus which was bus number 14. Additions of shunt capacitor at bus no 14 and 9 attained total line losses about 13.243 MW. The line loss reduced more by allocating shunt capacitor at two buses, but it was not a significant reduction compare with only one shunt capacitor placement 


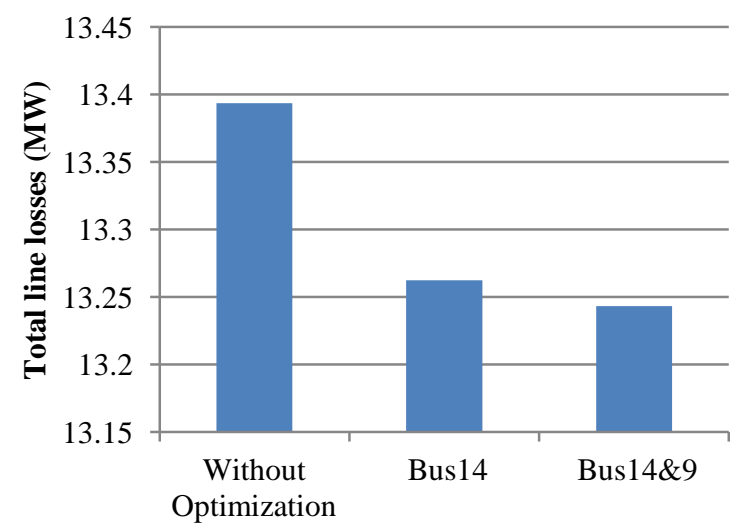

Figure 6. Power losses of base case before and after shunt capacitor placement

at the most sensitive bus no. 14. Further simulation has been conducted to determine the optimum sizing of shunt capacitor for increasing $100 \%$ load. The simulations run beyond two scenarios. The first scenario was done by allocating shunt capacitor at the most sensitive bus which was bus no. 14. The second scenario simulated by allocating two capacitors at bus no. 14 and 9.

Table 6 present the results which are optimum size of the capacitor (Qc), power losses and loss reduction ratio. Optimum shunt capacitor size is determined 23.982 Mvar with allocation shunt capacitor at bus no. 14. Power loss reduced to be 65.5019 MW and the loss reduction ratio is approximately $3.1693 \%$. Other result shows that optimum shunt capacitor size is determined about 28.53 Mvar for the allocation shunt capacitors at bus no. 14 and 9 . The power loss is reduced up to $64.9233 \mathrm{MW}$ and the loss reduction ratio about $4.0247 \%$

Table 6.

Optimum size of shunt capacitor and power losses for increasing $100 \%$ load

\begin{tabular}{llll}
\hline $\begin{array}{l}\text { Optimal } \\
\text { Location }\end{array}$ & Qc (Mvar) & PL (MW) & $\begin{array}{l}\text { Loss Reduction } \\
\text { Ratio (\%) }\end{array}$ \\
\hline Bus 14 & 23.982 & 65.5019 & 3.1693 \\
\hline Buses 14\&9 & 28.53 & 64.9233 & 4.0247 \\
\hline
\end{tabular}

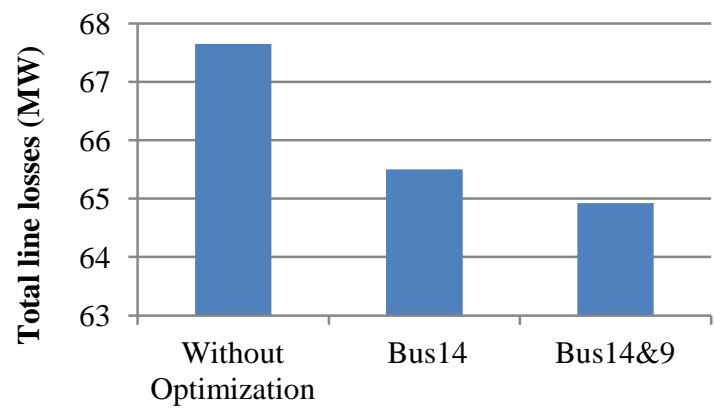

Figure 7. Power losses of increasing 100\% load before and after shunt capacitor placement

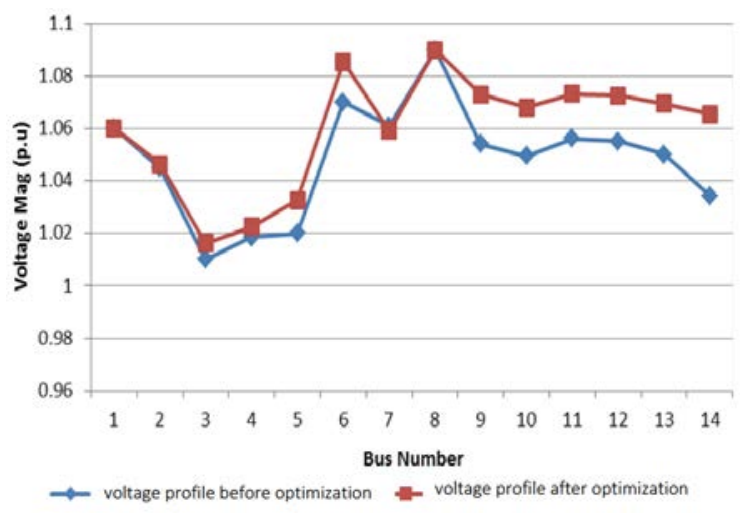

Figure 8. Comparison of voltage profile before and after optimization for the base case

Comparison of power losses before and after allocating shunt capacitors for increasing 100\% load is described in Figure 7. Total line losses before installing shunt capacitor reached up to 67.645 MW. Line losses decreased to be 65.501 MW after installing a shunt capacitor at the most sensitive bus no. 14. It decreased up to 4.932 MW by installing shunt capacitor at two buses no 14 and nine which considered the two highest sensitive buses in this study.

The results of shunt capacitor installation gave almost same trend for the base case and increasing $100 \%$ load. Installation of shunt capacitor device as the compensatory device has been proven to improve power losses on the line in the IEEE 14 bus power system. There can be figured out that proposing shunt capacitor at the most sensitive bus was able to reduce line losses significantly.

\section{Voltage Profile Before and After Optimization}

A series of simulation have been conducted to determine optimum candidate bus and optimum sizing to propose shunt capacitor in order to improve line losses. Voltage profile is the important parameter to assess the power system performance. Figure 8 and Figure 9 give detailed information about the voltage profile before and

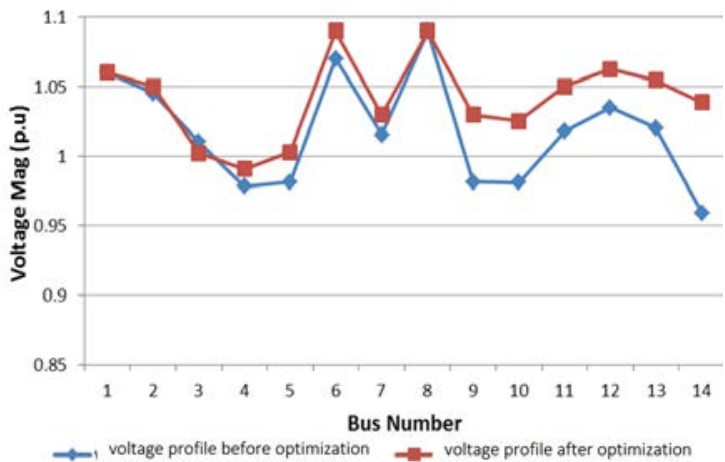

Figure 9. Voltage profile comparison before and after optimization for $200 \%$ load 


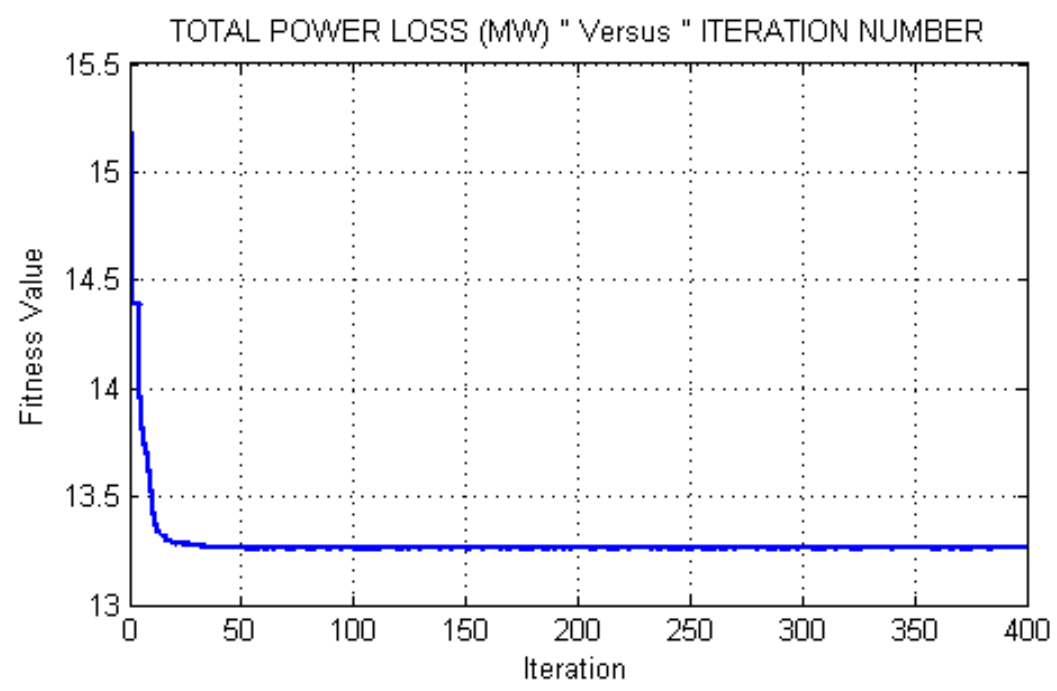

Figure 10. Fitness value and iteration of the weakest bus for base case

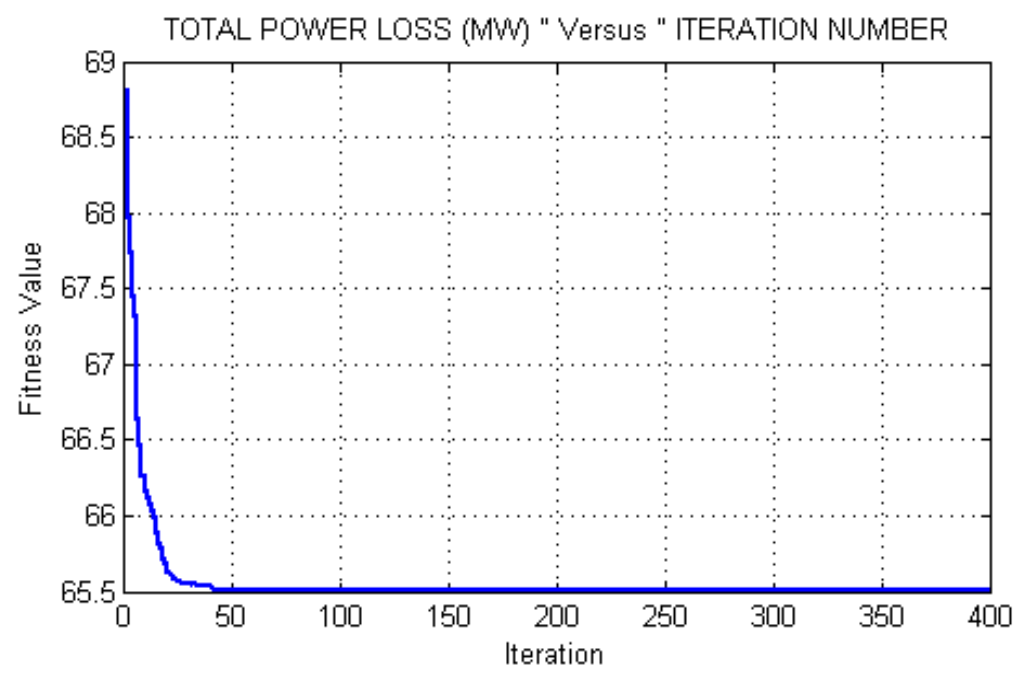

Figure 11. Fitness value and iteration number of the weakest bus for increasing $100 \%$ load

after optimization at each bus. The optimization was done by installing shunt capacitor at the most sensitive bus no. 14 .

Figure 8 shows the voltage profiles before and after optimization for the base case which the loading factor was $100 \%$ load. It can be seen that the voltage profile improve almost at all load busses after installing shunt capacitor at the most sensitive bus no. 14. Voltage profile seems to be increased significantly at the most sensitive bus no 14.

In another result, Figure 9 shows the comparison of voltage profile before and after optimization by installing shunt capacitor at bus no. 14 as the most sensitive bus. Voltage profile improved significantly at the load bus. It also shows that voltage profile of the most sensitive bus improved well by installing shunt capacitor at this bus. Furthermore, it influences voltage profile for other buses by improving the voltage which means giving better performance on the generator itself.
PSO simulates with population size of 40 along 400 iterations to obtain the best fitness or final solution for base case and increasing 100\% load. The performance of the simulations displayed on the Figure 10 and Figure 11. It shows that the particles iterated to search the best fitness value over the solution space and finally determine the best solution. Constant fitness value after initial iterations indicates that the particles start to find the best possible solution up to 400 iterations.

\section{E. Validation}

Power system efficiency becomes researchers' concern to minimize losses on distribution network over the system. They proposed some additional devices as compensators to minimize losses. It needs to determine optimum dimensions and placement of compensator devices through various computational optimizations in finding solutions. 
Table 7.

Validation of proposed method

\begin{tabular}{|c|c|c|c|c|c|}
\hline & Iethod & & Case & & $\begin{array}{l}\text { asing } \\
\text { load }\end{array}$ \\
\hline & $\begin{array}{l}\text { PL before } \\
\text { opt. } \\
\text { (MW) }\end{array}$ & 13. & & & \\
\hline & $\begin{array}{l}\text { PL after } \\
\text { opt. }\end{array}$ & 13. & & 68 & \\
\hline HSA & Opt. Loc. & 9 & 14 & 9 & 14 \\
\hline & Qc & 24.55 & 6.95 & 134.4 & 19.26 \\
\hline & $\begin{array}{l}\text { Loss } \\
\text { Reduction } \\
\text { ratio }\end{array}$ & 0.4 & & 2.6 & \\
\hline & $\begin{array}{l}\text { PL before } \\
\text { opt. } \\
\text { (MW) }\end{array}$ & 13. & & & \\
\hline & PL after opt. & 13. & & 64 & \\
\hline PSO & Opt. Loc. & 9 & 14 & 9 & 14 \\
\hline & Qc & 8.38 & 8.38 & 28.52 & 28.52 \\
\hline & $\begin{array}{l}\text { Loss } \\
\text { Reduction } \\
\text { ratio }\end{array}$ & 1.1 & & 4.0 & \\
\hline
\end{tabular}

Balachennaiah et al. [13] carried out a simulation study to determine the optimal location of static var compensator (SVC) to minimize real power loss and improve voltage stability using harmony search algorithm. Their study was also performed on IEEE 14 bus power system and conducted under different loading from the normal load (100\% loads) up to $200 \%$ load.

The proposed method has been tested by simulating Balachennaiah et al. data on the proposed method to find optimal location of SVC in order to minimize real power loss. The comparison results of HSA and proposed method are illustrated in Table 7 for normal load and increasing $100 \%$ load.

Table 7 shows that both HSA and proposed method determined the optimal placement was at bus 9 and 14 either for normal load and increasing $100 \%$ load. HSA recorded $0.44 \%$ reduction for normal load and $2.34 \%$ for increasing $100 \%$ load. Meanwhile proposed method recorded $1.12 \%$ reduction ratio and it obtained up to $4.02 \%$ for increasing $100 \%$ load. Proposed method recorded better reduction ratio compared with HSA.

\section{Conclusion}

Simulations have been performed to determine the optimum location and sizing of shunt capacitor in order to minimize line losses on the distribution network of IEEE 14 bus power system. PSO was proposed to find the best solution for shunt capacitor placement and sizing.
The IEEE 14 bus power system was carried out under normal load and further increase the load $100 \%$ than base case (200\%). Based on finding and discussion, the conclusion of the present study is that shunt capacitor placement proved to be able to minimize line loss on power system distribution. Optimum placement of shunt capacitor under normal load was obtained at the most sensitive bus no. 14 and the optimum size determined about 8.17 Mvar. Loss reduction ratio was $0.98 \%$ for this scenario. The optimum location of shunt capacitor under loading factor of 2 or $200 \%$ load was also obtained at the bus no. 14. The optimum size of capacitor determined about 23.98 Mvar with loss reduction ratio obtained up to $3.17 \%$. PSO was successfully also able to achieve multi-objective in finding the best solutions of capacitor placement and sizing.

\section{ACKNOWLEDGEMENT}

The author would like to thank Ditlitabmas, Ministry of Ristekdikti, Indonesia for providing financial support under PUPT Research Scheme with contract no. 632/UN27.21/LT/2016.

\section{REFERENCES}

[1] I. Ziari, "Planning of Distribution Networks for Medium Voltage and Low Voltage," Queensland University of Technology, 2011.

[2] A. Swarnkar et al., "Optimal placement of fixed and switched shunt capacitors for large-scale distribution systems using genetic algorithms," in IEEE PES Innovative Smart Grid Technologies Conference Europe (ISGT Europe), 2010, pp. 1-8.

[3] A. A. El-Fergany and A. Y. Abdelaziz, "Capacitor allocations in radial distribution networks using Cuckoo Search Algorithm," IET Gener. Transm. Distrib., vol. 8, no. 2, pp. 223-232, Feb. 2014.

[4] Y.-Y. Hong and B.-Y. Chen, "Locating switched capacitor using wavelet transform and hybrid principal component analysis network," IEEE Trans. Power Deliv., vol. 22, no. 2, pp. 1145-1152, Apr. 2007.

[5] A. A. Abou El-Ela et al., "Optimal capacitor placement in distribution systems for power loss reduction and voltage profile improvement,” IET Gener. Transm. Distrib., vol. 10, no. 5, pp. 1209-1221, Apr. 2016.

[6] M. Yarmohamadi and M. Taghikhani, "Capacitor Placement Optimization in Transmission System Using Hybrid PSO and HBMO Algorithms," Int. J. Energy Power, 2012, vol. 01, pp. 26-30.

[7] X. Su et al., "PSO and Improved BSFS Based Sequential Comprehensive Placement 
and Real-Time Multi-Objective Control of Delta-Connected Switched Capacitors in Unbalanced Radial MV Distribution Networks,” IEEE Trans. Power Syst., vol. 31, no. 1, pp. 612-622, Jan. 2016.

[8] S. Neelima and P. S. Subramanyam, "Optimal capacitor placement in distribution networks for loss reduction using differential evolution incorporating dimension reducing load flow for different load levels,” in IEEE Energytech, 2012, pp. 1-7.

[9] S. Soto and V. Hinojosa, "Stochastic optimal allocation of reactive power banks for system loss minimization,” IEEE Lat. Am. Trans., vol. 14, no. 4, pp. 1980-1987, Apr. 2016.

[10] I. Hasan et al., "Losses reduction and voltage improvement using optimum capacitor allocation by PSO in power distribution networks," IREMOS, vol. 06, no. 04, pp. 1219-1226, 2013.

[11] Lingwen Gan et al., "Optimal power flow in tree networks," in 52nd IEEE Conference on Decision and Control, 2013, pp. 2313-2318.

[12] J. Robinson and Y. Rahmat-Samii, "Particle Swarm Optimization in Electromagnetics," IEEE Trans. Antennas Propag., vol. 52, no. 2, pp. 397-407, Feb. 2004.

[13] P. Balachennaiah et al., "Optimal location of SVC for real power loss minimization and voltage stability enhancement using harmony search algorithm," Int. J. Electr. Eng. Technol., vol. 5, no. 1, pp. 26-34, 2014. 